\title{
Evaluation of Cementitious Fire Resistive Material in Steel Structures Using UL 263 International Standards
}

\author{
ERFAN KAZEMI ${ }^{1 *}$ and HOSSEIN EMAM JOMME² \\ ${ }^{1}$ Master's Degree student in the field Civil Engineering, \\ Earthquake, Islamic Azad University (IAU), West Tehran Branch, Iran. \\ ${ }^{2}$ Professor of Civil Engineering Department, Islamic Azad University (IAU), West Tehran Branch, Iran. \\ http://dx.doi.org/10.12944/CWE.11.Special-Issue1.06
}

(Received: July, 2016; Accepted: August, 2016)

\begin{abstract}
Considering the fact that constructional steel loses half of its thermal resistance under a certain temperature of a range of 550-550 C, therefore, as per UL 263 and ASTM-E119 international standards, the thickness of spraying fireproof substance shall be made for all the sections to strengthen the structure. Whereas using these standards as per the structures used in Iran is subject to various opinions among engineers, here it has been tried that a certain part of these relations in proportion to the structures used in Iran shall be examined theoretically and practically.
\end{abstract}

Keywords: Constructional Steel, Thermal Resistance, Spraying Fireproof Substance.

\section{INTRODUCTION}

The issue of steel structures fireproof is one of the issues highly considered globally during the recent years. Considering firefighting and Tehran Municipality instructions on compulsion of making steel structures fireproof, cementitious materials is one of the materials accepted in Iran to fulfill this issue ${ }^{1}$. Firecut-F1 cement based fireproof substance which is used exclusively by Beta Engineering Group in Iran is one of these materials. Two important discussions of thermal controlling of steel sections to determine the level of resistance against fire as well as resistance term against steel sections fire is one of the issues to be considered before evaluation of fireproof substance.

\section{Fire proof Resistance Time}

The first discussion posed in the field of building resistance against fire is the time of structure elements resistance against fire, defined as "fire resistance term". The time of fire resistance of structure elements is determined when each of the following criteria occur':

1. Structure collapse, which is considered as inability to structure elements in continuing bearing applied loads.

2. Average increased temperature of surfaces not facing fire shall be 250F (121C).

3. The passing gases and/or flames shall be hot enough to flame the thread ball in the part not facing the fire.

4. Thermal limitation of steel occurs.

Unprotected constructional steel has a bending temperature point of $470-500 \mathrm{C}$, and loses roughly half of the relevant resistance under 500 $550 \mathrm{C}$ [5], which it is usually expected that it reaches such temperature within 5 minutes after flame (Table No. 2.1). Therefore, it is quite vulnerable against fire, which mainly needs resistance against fire. The main purpose of protecting structure against fire is to facilitate and expedite in adding, reducing damages 
imposed to the building, preventing development and progress of fire to adjacent buildings and preserving the life of aids and residents of the building. Of the criteria judged in determining the time to resistance against building fire, include distance between structure up to fire fighting station, type of structure application, seismic nature of region, etc. Determining the building resistance against fire, which is usually considered as one or two hours, shall be borne by the firefighting body.

\section{Determining Sections Controlling Level}

According to UL263 and ASTM E119 standards, structure members are classified into two groups of restrained and unrestrained which shall be fulfilled by a reliable designer and/or authority determining whether to apply the assembly in restrained or unrestrained manner. The unrestrained assembly calculation factors shall be used for both states of restrained and unrestrained of ceilingfloor and floor- ceiling designs. The ceiling- floor and floor- ceiling assemblies as well as beams may

Table 2.1

\begin{tabular}{lc}
\hline Time & Temperature \\
\hline $5 \mathrm{~min}$ & 538 \\
$10 \mathrm{~min}$ & 704 \\
$30 \mathrm{~min}$ & 843 \\
$1 \mathrm{~h}$ & 927 \\
$2 \mathrm{~h}$ & 1010 \\
$4 \mathrm{~h}$ & 1093 \\
8 & 1260 \\
\hline
\end{tabular}

be considered as restrained when they support the structure or the support has the ability to bear the thermal expansion throughout the maximum expected temperature. Those structures not compatible to this definition shall be considered as free in bending and expansion and shall be deemed as unrestrained ${ }^{3}$. The following table may be used to determine the controlling the building members:

It should be noted that the members thermal controlling definition differs from structural controlling definition and the relevant thermal definition shall be considered in fireproofing designing.

\section{Evaluation of Thickness of Fireproof Substance needed for a Steel Structure}

Whereas the temperature changes in the body are related to the body mass and surface of a certain part transmitting the heat, in calculation of thickness of fireproof substance, the minimum beam size is expressed as W/D. In this ratio, $W$ is the unit length weight of beam and $D$ is the common circumference between beam and applied fireproof substance. W/D is a standard determined by United States Steel Society for W8*28 section, which isd something between 0.8 and 0.819 .

In order to determine the fireproof thickness, different beams sizes may be designed in the set of following designs considering the following formula (S800, S700, P900 P800, P700, N800, N700, J900, J800, J700, G800, G700, D900, D800, D700, A900, A800, A700) [3]:

Table 3.1

Steel Structures

No. Type of Connection

Restrained Unrestrained

1 Steel beams bolted, welded or pivoted to the elements.

2 All the members participating in floor and ceiling system

$\checkmark$

$\checkmark$

(such as beam and slab, flat slabs, integrated beams) while

the floor or ceiling system is fastened to structure members

3 Various types of pre-fabricated floor and/or ceiling systems while the structure members are fastened to frame members and thermal potential of ceiling and/or floor system is strengthened by frame system and/or adjacent floor and/or ceiling structure. 


$$
\mathrm{T}_{1}=\frac{\left(\frac{W 2}{D 2}+0.6\right)(T 2)}{\left(\frac{W 1}{D 1}+0.6\right)}
$$

T1: fireproof substance thickness (in)

T2: tested fireproof substance thickness (in)

W2/D2= tested weight to unit length ratio

$\mathrm{W} 1 / \mathrm{D} 1=$ relevant weight to unit length ratio

\section{Calculation of Sections Fire exposed Surface}

As it may be seen in the following figure, for the beams, one side of the same is in concrete and the three other sides are exposed to fire. In fact, implementation of fireproof substance spraying operations shall be fulfilled for the parts exposed to fire. The following figure shows a section; the upper wing of this beam is not exposed to fire, as it is embedded in ceiling cover, and therefore shall not be considered in calculations [5]

In calculation of W1/D1 ratio, the following formula may be used to determine this ratio through conversion of unit:

$\frac{W}{D}=\frac{134}{A P}$

$\mathrm{Hp}$ : fire exposed surface circumference $(\mathrm{m})$ A: section area (m2)

Now we calculate a building real sample:

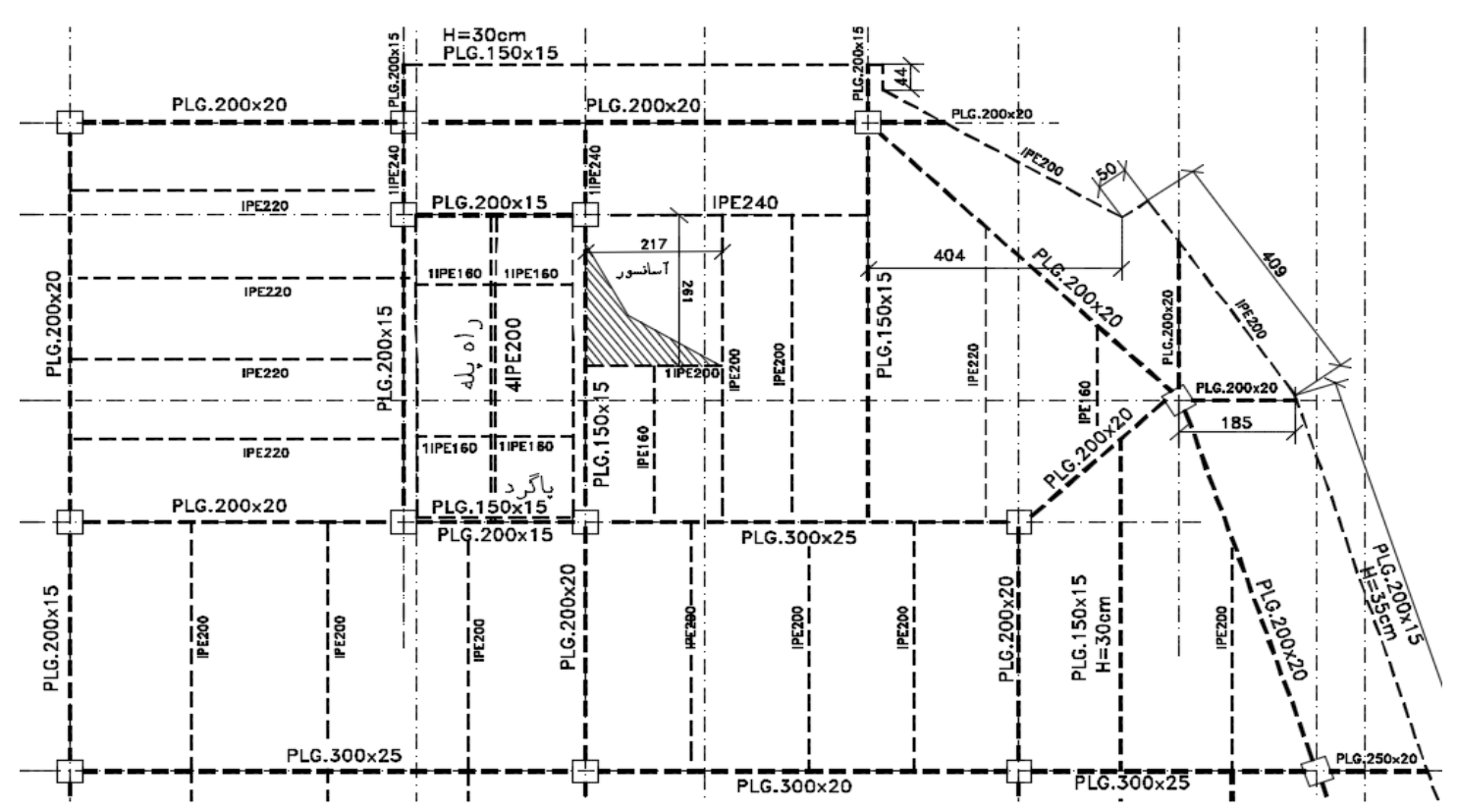

Fig. 1: Sample of Evaluated Drawing

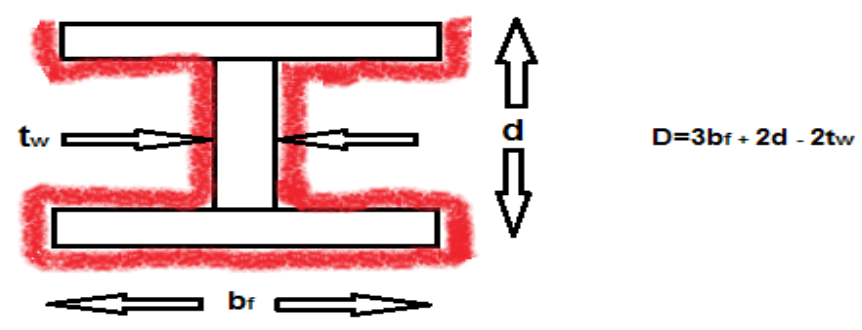

Fig. 3: Fire exposed Beam Circumference 


\section{Description of Structure and Primary Considerations}

Considering the foregoing, in this part the analysis and calculation of thicknesses of different sections of a steel structure is studied. First of all, 2 hours shall be considered as the time of fire resistance for structure. This drawing is of a floor of a steel structure in Tehran, with unprotected steel deck, connected to elements with studs.

As explained part 3, first of all the beams restraining status shall be studied. According to foregoing figure, and UL263 by law, all the connections are not able to expand and bending and are considered as restrained. Merely those connections which are consular shall be seen as unrestrained as they may expand from one side. The following table shows the restrained and unrestrained joints separately.

Table 5.1

\begin{tabular}{|c|c|c|c|}
\hline No. & Section Name & Restrained & Unrestrained \\
\hline 1 & IPE160 & $\checkmark$ & \\
\hline 2 & IPE200 & $\checkmark$ & $\checkmark$ \\
\hline 3 & IPE220 & $\checkmark$ & \\
\hline 4 & IPE240 & $\checkmark$ & \\
\hline 5 & PLG150×15 & $\checkmark$ & $\checkmark$ \\
\hline 6 & PLG200×15 & $\checkmark$ & $\checkmark$ \\
\hline 7 & PLG200×20 & $\checkmark$ & $\checkmark$ \\
\hline 8 & PLG250X20 & & $\checkmark$ \\
\hline 9 & PLG300X20 & $\checkmark$ & \\
\hline 10 & PLG300X25 & $\checkmark$ & \\
\hline
\end{tabular}

In UL263 standard, in order to determine the thicknesses of a network while an unprotected steel deck and concrete is used, D983 standard shall be applied. Usually this standard is also compatible with most of the structures constructed in Iran. the following table is used to determine tested W1/D1 ratio:

In the following the calculation of fireproof substance thickness is given for a restrained and an unrestrained section:

\section{PLG 300x25 Controlled Section}

Considering building structure drawing, fireproof substance thickness of this section shall be as per the following:

Calculation of $\mathrm{Hp}$ for three sides shall be as per the following:

$\mathrm{Hp}=3 \times 300+2 \times 500+4 \times 25-2 \times 12=1976 \mathrm{~mm}=$ $1.976 \mathrm{~m}$

Calculation of $A$ for the entire section:

$A=300 \times 25+500 \times 12+300 \times 25=21000 \mathrm{~mm}^{2}=$ $0.021 \mathrm{~m}^{2}$

$\frac{H p}{A}=\frac{1.976}{0.021}=126.66=94.09$

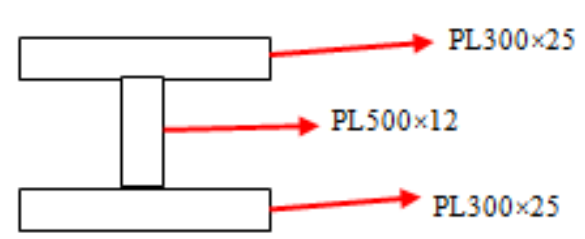

Table 5.2

\begin{tabular}{lccc}
\hline $\begin{array}{l}\text { Restrained thermal } \\
\text { capacity (hr) }\end{array}$ & $\begin{array}{c}\text { Unrestrained } \\
\text { thermal capacity (hr) }\end{array}$ & $\begin{array}{c}\text { Unrestrained beam } \\
\text { capacity (hr) }\end{array}$ & $\begin{array}{c}\text { Minimum beam } \\
\text { thickness W8x28 }\end{array}$ \\
\hline 1 & 1 & 1 & $7 / 16$ \\
$1-1 / 2$ & 1 & 1 & $7 / 16$ \\
$1-1 / 2$ & $1-1 / 2$ & $1-1 / 2$ & $5 / 8$ \\
2 & 1 & 1 & $7 / 16$ \\
2 & $1-1 / 2$ & $1-1 / 2$ & $5 / 8$ \\
2 & 2 & 2 & $13 / 16$ \\
3 & $1-1 / 2$ & $1-1 / 2$ & $5 / 8$ \\
3 & 2 & 2 & $13 / 16$ \\
3 & 3 & 3 & $1-5 / 16$ \\
\hline
\end{tabular}


Table 5.3

\section{No. Section Name Restrained Unrestrained}

\begin{tabular}{|c|c|c|c|}
\hline 1 & IPE160 & $\checkmark$ & \\
\hline 2 & IPE200 & $\checkmark$ & $\checkmark$ \\
\hline 3 & IPE220 & $\checkmark$ & \\
\hline 4 & IPE240 & $\checkmark$ & \\
\hline 5 & PLG150×15 & $\checkmark$ & $\checkmark$ \\
\hline 6 & PLG200×15 & $\checkmark$ & $\checkmark$ \\
\hline 7 & PLG200×20 & $\checkmark$ & $\checkmark$ \\
\hline 8 & PLG250X20 & & $\checkmark$ \\
\hline 9 & PLG300X20 & $\checkmark$ & \\
\hline 10 & PLG300X25 & $\checkmark$ & \\
\hline
\end{tabular}

Note: sections $7-10$ shall be considered as $10 \mathrm{~mm}$ as they are less than $10 \mathrm{~mm}$.

$$
\begin{aligned}
& \frac{W 1}{D 1}=\frac{134}{\frac{H P}{A}} \rightarrow \frac{W 2}{D 2}=\frac{134}{94.09}=1.42 \\
& =\frac{\left(\frac{W 2}{D_{2}}+0.6\right)(T 2)}{\left(\frac{W 1}{D_{1}}+0.6\right)}=\frac{(0.8+0.6) \times \frac{7}{16}}{(1.42+0.6)}=0.3 \mathrm{in}= \\
& T_{1}=25.4=7.62
\end{aligned}
$$

According to UL263 standard, regarding the thickness of the section of smaller than $3 / 8$ in, shall be considered as equal to $3 / 8 \mathrm{in}$ or roughly $10 \mathrm{~mm}$.

\section{IPE200 Unrestrained Section}

Regarding calculation of highly applicable sections such as IPE and CPE in European manual, steel structures fire resistance the $\mathrm{Hp} / \mathrm{A}$ ratio of the same has been calculated.

Concerning IPE200, the uncontrolled section is in this form, which is equal to 235.

IPE200:

$\frac{H p}{A}=235$

$\frac{W 1}{D 1}=\frac{134}{\frac{H P}{A}} \rightarrow \frac{W 2}{D 2}=\frac{134}{235}=0.57$
Considering the table, T2 laboratory leve for a section which is resistance against fire for two hours shall be equal to $13 / 16$.

$T_{1}=\frac{\left(\frac{W_{2}}{D_{2}}+0.6\right)(T 2)}{\left(\frac{W_{1}}{D_{1}}+0.6\right)}=\frac{(0.8+0.6) \times \frac{18}{16}}{(0.57+0.6)} 0.96 \mathrm{in}=$

$0.96 \times 25.4=24.38 \mathrm{~mm}$

Eventually, the fireproof substance thickness for uncontrolled IPE200 shall be equal to $24.38 \mathrm{~mm}$.

The other thicknesses of sections have been given in the following table:

\section{CONCLUSION}

In determining the thickness of fireproof substance, two major factors, i.e. resistance against fire and restraining nature of members are of special importance. In the bylaws applicable in Iran, restraining nature of the section is limited to the restraining nature of structure. Concerning building elements thermal analysis, thermal restraining nature is of certain importance. In this article, in addition to thermal resistance time determined by 3 rd discussion of national building regulations, some suitable thicknesses may be considered for sections considering their restraining features. Therefore, it is recommended that for the important buildings, the unrestrained factors are considered in designing for better safety of these structures. Designing suitable thicknesses may provide proper thermal resistance for the sections while eventually it minimizes financial and injuries and provides sufficient time for aids.

\section{ACKNOWLEDGEMENTS}

Mr. Majid Bahrami, managing director of Beta Engineering Group, who highly assisted the authors in provision of articles, is especially acknowledged. It is hoped that the academic society of the country may be assisted through developing other articles. 


\section{REFERENCES}

1. Regulations and Requirements of Steel Structures against Fire by Mineral spraying materials

2. Restraned Vs. Unrestrained Fire Ratings: A Practical Approach, By Socrates A. loannides, 1997

3. UL 263 - Underwriters Laboratories Inc., Standard for Safety Fire Tests of Building

\section{Constructions and Materials}

4. 3rd Chapter of national building regulations, protecting buildings against fire, 2013

5. Thickness Determination for Spray-Applied Fire Resistive Materials, John L. Ruddy and Socrates A. loannids; 2002

6. ASTM- E 119, Standard Test Methods for Fire Tests of Building Construction and Materials;2003 